\title{
Análise de um programa federativo para a formação continuada de treinadores de basquetebol
}

\author{
Vitor Ciampolini ${ }^{1}$ \\ Michel Milistetd ${ }^{1}$ \\ Jairo Luiz Socoowski de Anello ${ }^{2}$ \\ Tayná Iha ${ }^{1}$ \\ Juarez Vieira do Nascimento ${ }^{1}$
}

\section{RESUMO}

Objetivo: Programas para a formação de treinadores esportivos vêm passando por reformulações em uma escala global para melhor capacitar profissionais da área e atender às necessidades do campo prático. Assim, este estudo buscou analisar o programa de formação continuada de treinadores de basquetebol, oferecido por uma federação esportiva, no que tange à estrutura curricular, às estratégias de ensino e às percepções dos participantes. Metodologia: Participaram 68 treinadores de basquetebol e quatro instrutores. Dados quantitativos e qualitativos foram coletados a partir de anotações em diário de campo e aplicação de questionários. A análise dos dados se deu por meio de estatística descritiva e por meio da técnica de análise de conteúdo. Resultados e discussão: O programa foi organizado a partir de dois cursos e a estrutura curricular baseou-se na apresentação de temáticas aplicadas ao desenvolvimento e atuação do treinador esportivo por meio de estratégias de ensino diretivas, interativas e reflexivas. $O$ relato predominantemente positivo dos treinadores sugere a contribuição do programa na capacitação dos indivíduos para o aprimoramento da prática profissional. Conclusão: Destaca-se a importância da organização de programas federativos para a formação de treinadores a partir de um currículo voltado às demandas práticas de treinadores e por meio de estratégias de ensino ativas.

Palavras-chave: Formação profissional. Esporte. Currículo. Ensino.

\footnotetext{
${ }^{1}$ Universidade Federal de Santa Catarina, Florianópolis - SC, Brasil.

2 Secretaria de Esportes de Joinville, Joinville - SC, Brasil.
}

\section{Correspondência:}

Vitor Ciampolini. Rua Moraes, 109, Campeche, CEP 88063-274, Florianópolis - SC, E-mail: vciampolini@gmail.com 


\section{Analysis of a federative program for the continuing education of basketball coaches}

\section{ABSTRACT}

Objective: Coach education programs have been going through modifications on a global scale to better train individuals and meet the needs of the practical field. Thus, this study aimed to analyze the continuing education program for basketball coaches offered by a sports federation with regard to the curriculum structure, teaching strategies, and participants' perceptions. Methodology: 68 basketball coaches and four instructors participated. Quantitative and qualitative data were collected through field note journaling and a survey. Data analysis was performed using descriptive statistics and content analysis technique. Results and discussion: The program was organized in two courses and the curriculum structure was based on the presentation of topics applied to the development and practice of the sports coach through directive, interactive, and reflective teaching strategies. The predominantly positive perception of coaches suggests the contribution of the program in the training of individuals for the improvement of their practice. Conclusion: We highlight the pivotal role played by sports federations in organizing continuing education programs based on a curriculum focused on the practical demands of coaches and through active teaching strategies.

Keywords: Professional training. Sports. Curriculum. Teaching.

\section{Análisis de un programa federativo para la formación continua de entrenadores de baloncesto}

\section{RESUMEN}

Objetivo: Los programas de entrenamiento para entrenadores deportivos han sido sometidos a revisiones a escala mundial para entrenar mejor a los profesionales y satisfacer las necesidades del campo práctico. Por lo tanto, este estudio buscó analizar el programa de educación continua para entrenadores de baloncesto, ofrecido por una federación deportiva, con respecto a la estructura curricular, las estrategias de enseñanza y las percepciones de los participantes. Metodología: Participaron 68 entrenadores de baloncesto y cuatro instructores. Se recogieron datos cuantitativos y cualitativos de las notas de campo y cuestionarios. El análisis de datos se realizó mediante estadística descriptiva y la técnica de análisis de contenido. Resultados y discusión: El programa se organizó en dos cursos y la estructura curricular se basó en la presentación de temas aplicados al desarrollo y desempeño del entrenador deportivo a través de estrategias de enseñanza directivas, interactivas y reflexivas. El informe predominantemente positivo de los entrenadores sugiere la contribución del programa a la capacitación de individuos para la mejora de la práctica profesional. Conclusión: Destacamos la importancia de organizar programas federativos para la capacitación de entrenadores basadas en un plan de estudios centrado en las demandas prácticas de los entrenadores y mediante estrategias de enseñanza activas.

Palabras Clave: Formación profesional. Deporte. Currículo. Enseñanza. 


\section{Introdução}

No Brasil, o período de formação inicial em Educação Física é destinado à compreensão ampliada de conhecimentos de base aplicados a área (fisiologia, pedagogia, psicologia, biomecânica, entre outros) e de desenvolvimento de competências gerais para a atuação profissional qualificada (diagnosticar, pesquisar, analisar, avaliar, intervir, entre outras) (BRASIL, 2004; MILISTETD et al., 2017). Posteriormente a esta etapa, a formação continuada é o período de qualificação específica do profissional e importante meio para aprimoramento da atuação a partir da reavaliação das ações cotidianas e concepções prévias (AZEVEDO et al., 2010). No caso específico dos treinadores esportivos, programas de formação continuada são normalmente oferecidas por federações e entidades esportivas visando o desenvolvimento de competências específicas à modalidade representada pela entidade organizadora (MILISTETD et al., 2014).

Apesar destes programas estarem contribuindo mundialmente para o desenvolvimento profissional de treinadores (TRUDEL; GILBERT; WERTHNER, 2010; MILISTETD et al., 2016), percepções negativas ainda são identificadas em estudos conduzidos na área (PIGGOTT, 2012; STOSZKOWSKI; COLLINS, 2016). De modo geral, o descontentamento está normalmente associado à maneira em que o currículo dos programas está estruturado e que as estratégias de ensino são implementadas (PIGGOTT, 2012; NELSON; CUSHION; POTRAC, 2013). Assim, as críticas concentram-se em currículos préestabelecidos que não consideram a experiência prévia e a realidade dos participantes e estratégias de ensino diretivas que não possibilitam a reflexão e colaboração entre os treinadores (PIGGOTT, 2012; NELSON; CUSHION; POTRAC, 2013). No entanto, quando a estrutura curricular é organizada para atender às necessidades dos participantes e as estratégias de ensino facilitam o engajamento dos treinadores com o conteúdo e com seus pares, percepções positivas são identificadas (CIAMPOLINI et al., 2019). Deste modo, no intuito de potencializar a qualidade e a contribuição destes programas formativos, a adoção de um paradigma de aprendizagem pode ser uma alternativa ao tradicional paradigma instrucional normalmente articulado (BARR; TAGG, 1995).

Segundo Barr e Tagg (1995), no paradigma de aprendizagem busca-se promover o aprendizado dos indivíduos por meio da descoberta e construção de conhecimento de forma auxiliada em ambientes de cooperação entre os aprendizes. Este opera como uma alternativa ao paradigma instrucional, o qual objetiva oferecer uma instrução de qualidade, a seleção de bons conteúdos e transferir conhecimentos importantes dos experts (instrutores) aos aprendizes (BARR; TAGG, 1995). Apesar do paradigma de aprendizagem apresentar elevado potencial como meio de formação na atual sociedade da informação 
(JARVIS, 2007), o estabelecimento de estratégias adequadas orientadas por seus princípios interativos e construtivistas ainda é um desafio à formação profissional (BARR; TAGG, 1995; CULLEN; HARRIS; HILL, 2012; WEIMER, 2013).

Se por um lado, estudos internacionais já demonstram preocupação quanto ao aprimoramento dos programas de formação de treinadores (CIAMPOLINI et al., 2019), no Brasil, investigações desta natureza são reduzidas, principalmente no contexto federativo (MILISTETD et al., 2016). No caso particular da Confederação Brasileira de Basquetebol (CBB), identificou-se um esforço para a construção de um programa nacional de formação de treinadores, que não foi mantido ao longo dos anos (MILISTETD et al., 2016). Assim, a ausência de um programa estruturado de certificação em nível nacional faz com que as federações estaduais da modalidade tenham que desenvolver as próprias ações para auxiliar na capacitação de treinadores. Neste cenário, a Federação Catarinense de Basketball (FCB) oferece cursos para a formação continuada de treinadores vinculados aos projetos fomentados pela entidade (FCB, 2018).

Em 2017, a FCB buscou modificar os cursos voltados ao aprimoramento dos conhecimentos técnicos e apostou em um programa direcionado ao desenvolvimento de competências mais amplas para a atuação. Para isso, buscou-se a organização de estratégias de ensino que favorecessem ambientes mais colaborativos e reflexivos ao longo dos encontros. Contudo, mudanças de paradigmas são repletas de desafios e, quando se trata do ambiente educacional, investigações recentes têm buscado entender a percepção de treinadores esportivos quanto às novas propostas formativas (MORGAN et al., 2013; DRISKA; GOULD, 2014; PAQUETTE et al., 2014). Acredita-se que este estudo possa contribuir na lacuna investigativa acerca da reformulação de programas de formação de treinadores no Brasil, especialmente no tocante aos programas de formação continuada no âmbito federativo. Portanto, este estudo buscou analisar o programa de formação continuada de treinadores de basquetebol, oferecido pela FCB, no ano de 2017, no que tange a estrutura curricular, as estratégias de ensino e as percepções dos participantes.

\section{Metodologia}

Este estudo caracteriza-se como descritivo com delineamento de estudo de caso (YIN, 2011). No que se refere a abordagem do problema, optou-se pela adoção de métodos mistos (quantitativos e qualitativos), dado a análise qualitativa da estrutura curricular, das estratégias de ensino e das percepções relatadas pelos treinadores, bem como devido a representação numérica da percepção geral sobre a participação no programa investigado (CRESWELL; 
PLANO CLARK, 2011). Ademais, destaca-se a articulação do procedimento convergente paralelo, onde ambos os métodos são aplicados concomitantemente para a coleta de dados (CRESWELL; PLANO CLARK, 2011). Destaca-se que este estudo foi aprovado no Comitê de Ética em Pesquisa com Seres Humanos de uma universidade pública federal (parecer 3.606.190) e os participantes assinaram um termo de consentimento para participação na pesquisa. Além disso, consentimento foi dado pela entidade investigada para que seu nome fosse apresentado neste estudo.

\section{O PROGRAMA INVESTIGADO}

Em 2017, o currículo elaborado pela FCB para o programa de formação de treinadores buscou integrar temáticas que contribuíssem para o desenvolvimento dos conhecimentos profissionais, interpessoais e intrapessoais do treinador esportivo (ICCE, 2013). Os conhecimentos profissionais representam os conteúdos específicos da área necessários para a atuação efetiva (como os conhecimentos da modalidade esportiva e as ciências básicas - fisiologia, pedagogia, psicologia, biomecânica) (CÔTÉ; GILBERT, 2009). Os conhecimentos interpessoais referem-se à capacidade de relacionamento e comunicação do indivíduo para interagir com pares, pais, atletas e outros profissionais (CÔTÉ; GILBERT, 2009). Por fim, os conhecimentos intrapessoais compreendem a capacidade do indivíduo de reflexão sobre a própria prática e os contextos que está inserido (CÔTÉ; GILBERT, 2009).

Assim, três cursos presenciais foram idealizados para o ano. Inicialmente, dois cursos de nível 1 (realizados nos meses de abril e junho, respectivamente) tiveram como intuito: a) tratar assuntos gerais da aprendizagem, desenvolvimento e atuação do treinador esportivo e; b) atender, em cada, metade do grande grupo de treinadores do estado de Santa Catarina. O primeiro curso de nível 1 foi realizado na região oeste do estado e o segundo na região litorânea. Posteriormente, um curso de nível 2, realizado no mês de agosto, abordou assuntos mais aprofundados sobre o treinamento esportivo e reuniu todos os treinadores do estado para o fechamento do processo formativo. Cada curso contou com carga horária total de 12 horas, sendo quatro na sexta-feira (das $18: 30$ às $22: 30$ ) e oito no sábado (das 08:00 às $12: 00$ e das $13: 00$ às $17: 00)$.

A participação no programa era obrigatória para treinadores filiados à $\mathrm{FCB}$ que estavam envolvidos em 2017 no projeto "Basquete para o Amanhã", o qual tinha um propósito educacional e atendia crianças e jovens de 10 a 15 anos de idade em todo o estado. Treinadores de basquetebol do estado vinculados a outros projetos (sejam da FCB ou de outras entidades) ou atuantes em outras categorias (sub17, sub19 e adulta) poderiam participar do programa se demonstrassem interesse e contactassem a FCB previamente. Além disso, graduandos em Educação Física que conduziam estágios supervisionados nas 
equipes integradas no projeto "Basquete para o Amanhã" também poderiam participar do programa.

\section{PARTICIPANTES}

Noventa e um treinadores de basquetebol do Estado de Santa Catarina participaram dos cursos de formação. Contudo, 68 treinadores (47 homens e 21 mulheres) com média de idade de 33 anos (mínima 19 e máxima 72) responderam os questionários na íntegra e aceitaram participar da pesquisa. Destes, 19 (27,9\%) estavam cursando Educação Física, 29 (42,7\%) possuíam ensino superior completo e $20(29,4 \%)$ eram pós-graduados. De modo geral, os treinadores atendem crianças e jovens do projeto "Basquete para o Amanhã" com o objetivo de formação esportiva e social. A tabela 1 apresenta informações acerca da experiência dos participantes como atletas e treinadores.

Tabela 1 - Caracterização dos participantes do estudo

\begin{tabular}{|c|c|c|c|c|c|c|c|c|c|c|}
\hline & \multicolumn{4}{|c|}{ Duração (em anos) } & \multicolumn{6}{|c|}{ Contexto } \\
\hline & \multirow{2}{*}{ Mínimo } & \multirow{2}{*}{ Máximo } & \multirow{2}{*}{ Média } & \multirow{2}{*}{ DP } & \multicolumn{2}{|c|}{ Recreacional } & \multicolumn{2}{|c|}{ Amador } & \multicolumn{2}{|c|}{ Profissional } \\
\hline & & & & & $\mathbf{n}$ & $\%$ & $\mathbf{n}$ & $\%$ & $\mathbf{n}$ & $\%$ \\
\hline $\begin{array}{l}\text { Experiência } \\
\text { como atleta }\end{array}$ & 0 & 40 & 12,49 & 8,05 & 3 & 4,4 & 39 & 57,4 & 26 & 38,2 \\
\hline $\begin{array}{l}\text { Experiência } \\
\text { como treinador }\end{array}$ & $<1$ & 45 & 8,56 & 9,38 & 2 & 2,9 & 43 & 63,2 & 23 & 33,8 \\
\hline
\end{tabular}

DP = Desvio Padrão.

Nota $=$ Considerou-se contexto 'recreacional' a prática pelo lazer e nos ambientes escolares, 'amador' a participação em treinamentos e competições sem remuneração financeira e 'profissional' o exercício da profissão de atleta mediante remuneração financeira.

Além disso, quatro instrutores foram responsáveis por ministrar temáticas do próprio domínio ao longo dos cursos. Todos os instrutores tinham experiências prévias na docência de cursos de capacitação e de disciplinas no ensino superior. A Tabela 2 apresenta informações acerca dos instrutores envolvidos programa investigado:

Tabela 2 - Caracterização dos instrutores envolvidos no programa investigado

\begin{tabular}{lccc}
\hline & Idade & Escolaridade & $\begin{array}{c}\text { Anos de Experiência } \\
\text { Docente }\end{array}$ \\
\hline Instrutor 1 & 53 & Graduado & 29 \\
\hline Instrutor 2 & 34 & Doutor & 10 \\
\hline Instrutor 3 & 58 & Mestre & 30 \\
\hline Instrutor 4 & 40 & Doutor & 8 \\
\hline
\end{tabular}

\section{Procedimento de Coleta dos Dados}

Ao longo dos cursos, o primeiro autor deste estudo participou do programa investigado como observador não-participante (YIN, 2011). Desta maneira, o autor esteve presente nas salas de aula dos cursos, mas não integrou às estratégias de ensino adotadas pelos instrutores. As anotações em 
diário de campo foram realizadas de maneira estruturada, buscando descrever de maneira detalhada os conteúdos e as estratégias de ensino adotadas. Além disso, foi disponibilizado ao autor o material didático e o planejamento do programa investigado, o que contribuiu com as anotações durante os cursos. Destaca-se que o primeiro autor possuía experiências prévias com coleta de dados por meio de diários de campo, especificamente com relação às estratégias de ensino e procedimentos didáticos utilizados em cursos de formação de treinadores. Além disso, a trajetória do autor na prática e treinamento esportivo no basquetebol facilitou a compreensão de linguagens e discussões específicas da modalidade.

Após o término dos cursos de nível 1 e nível 2, os treinadores responderam a um questionário online elaborado pelos autores contendo questões abertas e de múltipla escolha acerca da satisfação com o curso e percepções gerais sobre as temáticas e atividades ministradas. O questionário abrangia as seguintes dimensões: percepção geral sobre os cursos; aspectos positivos e negativos dos cursos; conteúdos ministrados; estratégias de ensino adotadas; sugestões para aprimoramento. As questões de múltipla escolha se apresentavam em escala likert de 1 a 5 com as seguintes categorias: (1) péssima; (2) ruim; (3) regular; (4) boa; (5) ótima. Já as questões abertas referiam-se aos (a) aspectos positivos do programa; (b) aspectos negativos do programa e; (c) comentários adicionais. Ressalta-se que apenas os questionários respondidos integralmente foram incluídos no estudo.

\section{ANÁLISE dOS DADOS}

De modo a conduzir as análises dos dados quantitativos, realizou-se a importação das informações de uma planilha do software Microsoft Office Excel (versão 2010) para uma planilha do software IBM Statistical Package for the Social Sciences (SPSS - versão 23.0). Para os dados relacionados à idade, formação, duração e contextos de atuação como atleta e treinador, e satisfação com a participação no curso, aplicou-se estatística descritiva de média, mínimo, máximo, frequência relativa e desvio padrão. Já para os dados qualitativos, todas as anotações em diário de campo foram transcritas em um documento do software Microsoft Office Word (versão 2010). As transcrições foram apreciadas e discutidas pelos autores a fim de produzir uma descrição detalhada dos cursos quanto aos conteúdos abordados e às temáticas gerais propostas.

A técnica de análise de conteúdo com categorias estabelecidas à posteriori (BARDIN, 2011) foi empregada na análise dos dados das questões abertas. Este processo deu-se em três etapas: inicialmente, todas as respostas das questões abertas identificadas nos questionários foram importadas para um documento em branco do Microsoft Office Word; na sequência, a exploração do material contou com a leitura aprofundada dos dados e codificação das transcrições brutas em representações de conteúdo a partir da identificação de unidades de 
registro e, posteriormente, da organização destas em subcategorias e categorias, respectivamente. Finalmente, verificou-se a frequência da categorização criada $s$ categorias e subcategorias criadas para a elaboração do relatório de análise. Para análise dos dados, o software QSR NVivo (versão 11) auxiliou na organização das informações. De modo a garantir a confiabilidade da categorização, os pesquisadores discutiram o alinhamento conceitual interno das categorias, subcategorias e unidades de registro (homogeneidade interna) e a distinção destas com as demais (heterogeneidade externa) (PATTON, 1990). Tendo em vista que em determinados momentos as falas pertencentes às unidades de significado referiam-se a mais de uma unidade de registro, estas foram enquadradas no local de maior coerência.

\section{RESULTADOS}

\section{ESTRUTURA CURRICULAR E ESTRATÉGIAS DE ENSINO DOS CURSOS}

A partir da apreciação das temáticas, conteúdos e estratégias de ensino ministradas pelos instrutores durante os cursos de nível 1 e 2, conduziu-se uma sistematização das informações para apresentação em formato de quadro (veja o Quadro 1 abaixo). Assim como proposto inicialmente, verificou-se a condução de temáticas e conteúdos mais gerais sobre o desenvolvimento e a atuação do treinador no curso de nível 1. Posteriormente, o curso de nível 2 aprofundou nas temáticas ministradas e realizou uma sessão de treino prática, discutida e refletida com os participantes. No tocante às estratégias de ensino adotadas, identificou-se atividades de natureza diretiva (instrução direta, leituras de textos, apresentação de vídeos e imagens, entre outros) interativa (questionamentos, trabalho no grande grupo e em pequenos grupos) e reflexiva (reflexão individual e em grupo e aprendizagem baseada em problemas). Por fim, é importante acrescentar que entre os cursos de nível 1 e o curso de nível 2 , foi solicitado aos treinadores para que respondessem um portfólio contendo informações acerca da própria filosofia de treinamento, da trajetória até o ingresso nos projetos esportivos da federação, da percepção das próprias competências relacionadas à atuação profissional, dos atletas que treina, entre outros. Neste portfólio, deveriam também estar anexadas 10 sessões de treino aplicadas nos últimos meses. 
Quadro 1 - Descrição das temáticas, conteúdos e estratégias de ensino adotadas por cada instrutor nos cursos de nível 1 e 2 .

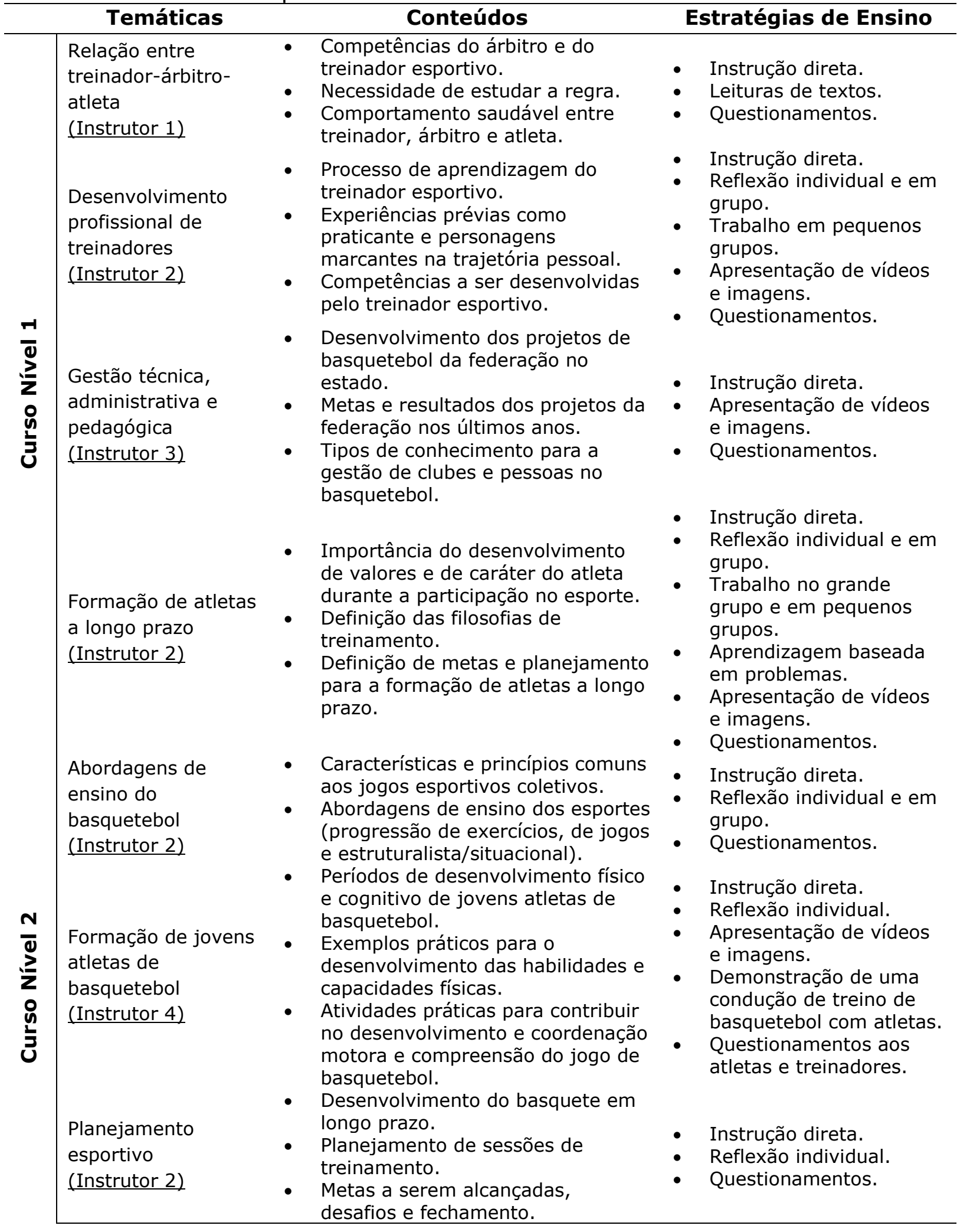

\section{PeRCEPÇÃo dos tReinadores SOBRe OS CURSOS}

Os resultados dos dados quantitativos acerca da percepção geral dos 
treinadores de basquetebol participantes do programa investigado revelaram que, em suma, 9 em cada 10 treinadores estão satisfeitos com o programa proposto (93\%). Ressalta-se que nenhum treinador percebeu o programa como ruim ou péssimo. A discriminação das porcentagens pode ser encontrada na Figura 1.

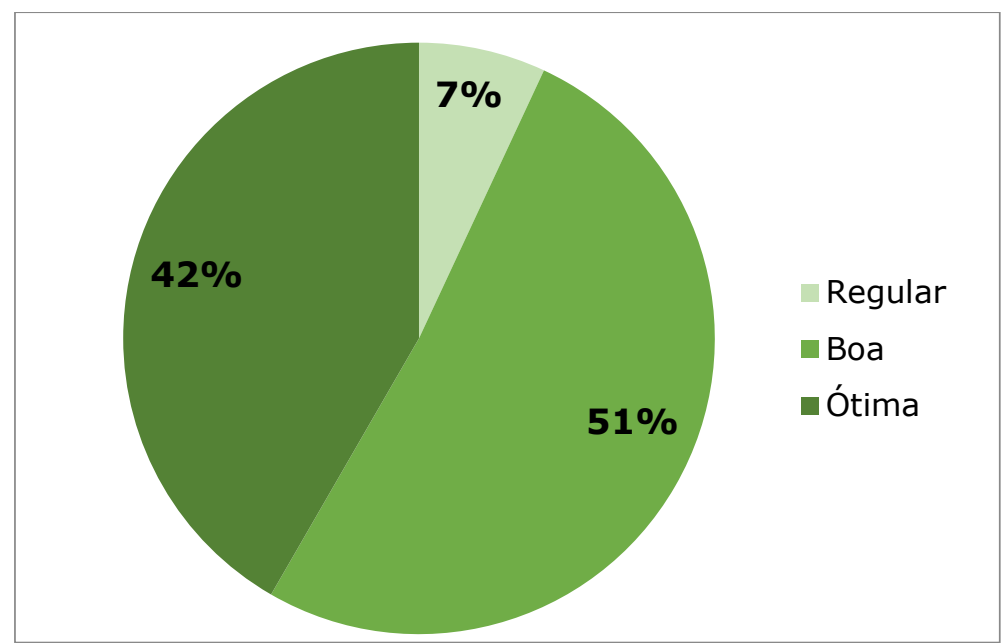

Figura 1 - Percepção geral dos treinadores acerca do programa investigado.

No que se refere à análise dos dados qualitativos referentes às percepções dos treinadores, a Figura 2 apresenta as categorias organizadas a partir da condução da técnica de análise de conteúdo (categorias, subcategorias e unidades de registro) bem como a discriminação da frequência de relatos identificados. De modo similar à análise quantitativa conduzida na percepção dos treinadores, os aspectos positivos à formação se sobressaíram $(f=82)$ quando comparados aos aspectos negativos $(f=29)$.

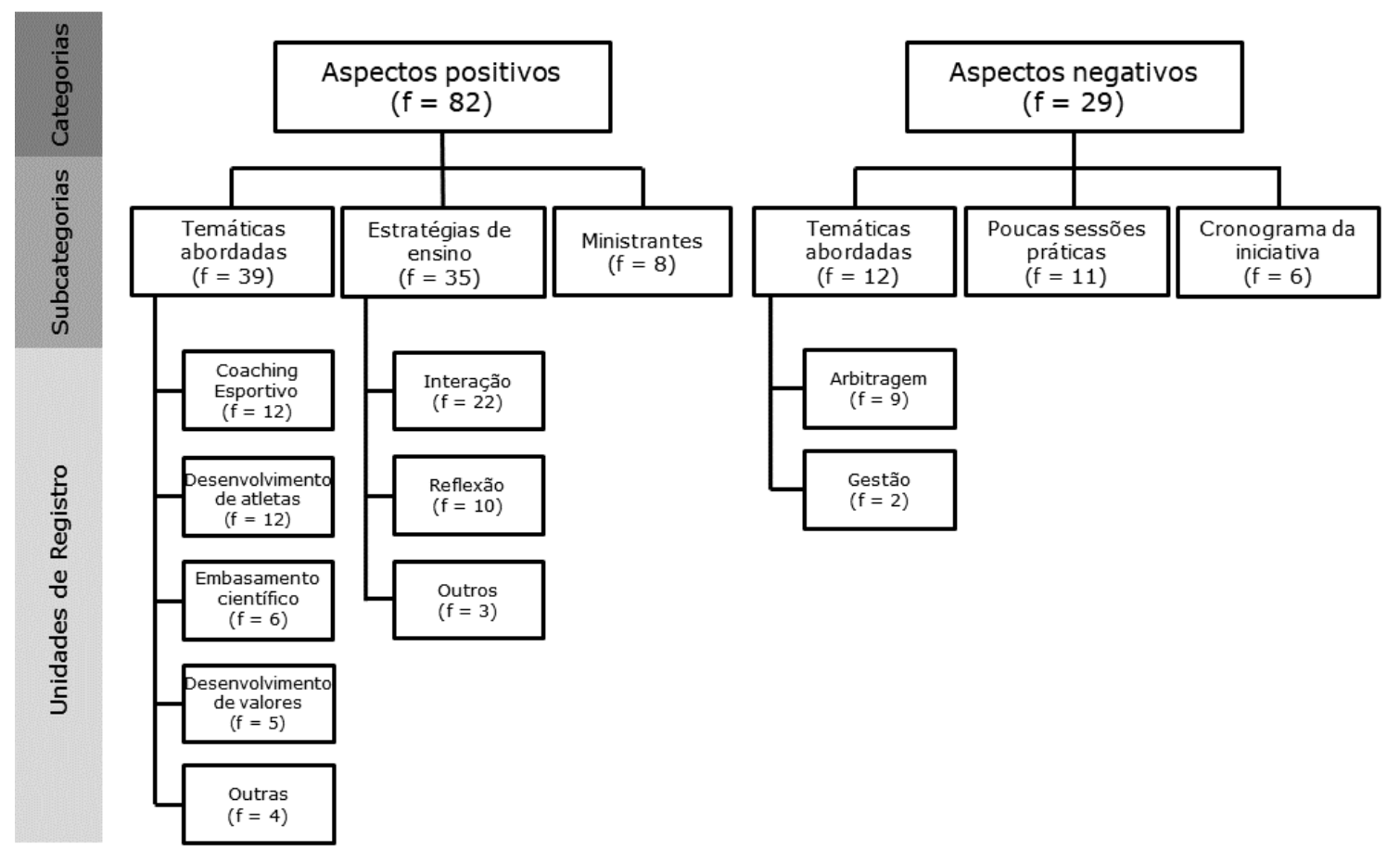

Figura 2 - Categorias de análise da percepção dos participantes. 


\section{ASPECTOS POSITIVOS À FORMAÇÃO}

Temáticas abordadas: As temáticas abordadas pelos instrutores foi o tema mais relatado positivamente pelos treinadores, onde se observou grande valor atribuído aos aspectos relacionados à aprendizagem e desenvolvimento do coaching esportivo $(f=12)$ : "Fiquei positivamente muito surpreso com a proposta e o cuidado da federação de falar sobre formação profissional, fugindo do convencional e tradicional pacote de exercícios ideais para cada idade" (T58). Os conteúdos e discussões relacionados ao desenvolvimento de atletas também foi a unidade de registro mais identificada das temáticas ( $f=12$ ): "Gostei da abordagem dos temas e a sua importância para as categorias iniciais. O basquete catarinense precisa ter esse olhar de cuidado para as categorias sub 12/13 e 15" (T7).

Apesar de se tratar de um programa de formação fora do contexto universitário, os treinadores apresentaram relatos positivos referente a utilização de estudos científicos e livros para embasar as falas dos instrutores ( $f$ = 6): "Achei muito valiosa a tentativa de aproximar o científico do profissional, nos fazendo rever nossas ações, princípios e valores" (T43). Por fim, as informações e reflexões acerca da importância do desenvolvimento de valores nas categorias de base também foram percebidas positivamente $(f=5)$ : "Louvável a iniciativa da federação em pensar o basquete como um todo, como formação além das quadras... Acho super válida a reflexão..." (T67).

Estratégias de ensino: As estratégias de ensino adotadas pelos instrutores foram mencionadas positivamente com grande frequência pelos treinadores, especialmente devido à natureza interativa ( $f=22$ ) das atividades propostas: "Achei o curso extremamente importante, pois nos colocou a pensar e avaliar nossas perspectivas como treinadores e educadores; nos permitiu uma valiosa interação treinador-treinador, onde pudemos expor pensamentos, dúvidas, dificuldades e trocas de experiências" (T43). A partir destas dinâmicas, treinadores puderam auxiliar no aprendizado dos pares, o que foi percebido positivamente principalmente por treinadores mais jovens: "Achei valiosa a troca de experiências com treinadores mais velhos" (T54).

Além disso, a busca por proporcionar aos treinadores oportunidades de reflexão também foi percebida positivamente ( $f=10$ ): "A fala do (Instrutor 2 ) não foi direcionada para a prática do basquetebol, mas nos fez refletir em todos os sentidos. Acho que muitos de nós estávamos precisando de outra visão, tanto para dentro da quadra quanto para fora" (T9). A partir de atividades desta natureza, treinadores puderam refletir acerca dos próprios comportamentos e maneiras para aprimora-los: "Através das perguntas feitas pelo instrutor, consegui observar o que melhorei durante o período em que trabalho com o basquetebol e o que posso fazer para melhorar ainda mais" (T12). 
Ministrantes: Por fim, observou-se também o relato positivo com relação aos ministrantes dos cursos devido ao domínio de conteúdos ( $f=8$ ): "[...] profissionais muitíssimo capacitados e com um vasto conhecimento..." (T42); e de conhecimento acerca de realidades internacionais: "A participação de um profissional com bagagem teórica e com a visão ampla do esporte mundial" (T47). Ademais, a proximidade do programa investigado aos aspectos científicos e universitários foi novamente mencionada: "A presença de um professor que está inserido na universidade e que possui experiência com estudos científicos acrescentou muito em suas falas" (T34).

\section{ASPECTOS NEGATIVOS À FORMAÇÃo}

Temáticas abordadas: Apesar de ter sido mencionada positivamente pelos treinadores, também foram identificados relatos negativos acerca das temáticas abordadas nos cursos ( $f=12$ ), principalmente acerca de conteúdos relacionados à arbitragem: "Achei desnecessária a parte da fala sobre a arbitragem, foi falado muito sobre a percepção pessoal do instrutor e não sobre treinadores, árbitros e atletas" (T6); "A parte de arbitragem poderia ser voltada para regras menos conhecidas, ou soluções para um entendimento entre as partes envolvidas com o basquetebol" (T13). Além disso, os conteúdos relacionados à gestão também receberam relatos negativos: "Muitos números e vídeos antigos da FCB, onde poderia ser tomado esse tempo para outras atividades. A fala da FCB tem que ser mais direta e rápida..." (T9).

Poucas sessões práticas: A falta de sessões práticas no curso de nível 1 foi percebida negativamente pelos treinadores participantes do programa investigado ( $f=11$ ), onde se percebeu a utilização demasiada do tempo para assuntos teóricos: "Muito tempo em palestras e pouco tempo vendo treinos ao vivo como foi demonstrado na segunda etapa da formação" (T37). Assim, percebeu-se que os treinadores atribuem tal valor às sessões práticas devido à oportunidade de aprimoramento de competências nestas atividades: "Penso que faltou a parte prática em determinadas situações, nas quais só corrigimos praticando" (T8).

Cronograma: No que tange os relatos negativos ao cronograma estipulado para a condução dos cursos ( $f=6$ ), identificou-se percepção em comum acerca do início das atividades na sexta-feira às 18:30h: "Iniciar na sexta à noite faz com que os treinadores que trabalham se desloquem com pressa e cansados, podendo ocorrer algum acidente [...] seria melhor iniciar o curso no sábado de manhã" (T34).

\section{DISCUSSÃO}

Apesar das discussões nas últimas décadas sobre a necessidade da 
transição dos paradigmas educacionais e da atualização de propostas curriculares, a perspectiva passiva do aprendiz e instrucional do professor ainda é vista como natural em contextos formativos (BARR; TAGG, 1995; CULLEN; HARRIS; HILL, 2012; WEIMER, 2013). Ademais, os paradigmas instrucional e de aprendizagem não devem ser vistos como antagônicos, especialmente quando se considera que a transição entre estes deve ser "um processo de modificações graduais em que se altera diversas partes da organização em busca de uma nova visão para o todo" (BARR; TAGG, 1995, p. 20). Em vista disso, com base nas observações e análises conduzidas sobre a estrutura curricular, as estratégias de ensino e as percepções dos treinadores a respeito do programa de formação da FCB no ano de 2017, identificou-se um panorama em transição. O que se percebeu, neste caso, foi a integração de alguns princípios do paradigma de aprendizagem ao paradigma instrucional instalado, tais como: estratégias de ensino ativas por parte de alguns instrutores; articulação e fomento da participação dos treinadores durante os cursos e; busca pelo desenvolvimento de competências dos participantes.

No caso da Confederação Canadense de Golfe, no início da década de 1990, a busca pelo aprimoramento do programa de formação de treinadores da entidade a partir do contato com professores do contexto universitário levou a uma transição completa da proposta inicial (PAQUETTE; TRUDEL, 2018). Se anteriormente, a estrutura curricular baseava-se em princípios instrucionais e diretivos onde se ensinava "as melhores técnicas para o ensino da modalidade"; posteriormente, focou-se na condução de aulas abertas (sem estrutura prédefinida), dialogadas e reflexivas, construídas a partir das necessidades relatadas pelos treinadores (PAQUETTE; TRUDEL, 2018). Apesar desta transição possivelmente ter posicionado tal programa mais próximo do paradigma de aprendizagem, os instrutores da entidade encontravam dificuldades com a falta de diretrizes e os treinadores passaram a perceber negativamente os cursos, 0 que acarretou em uma nova reestruturação curricular e busca pelo ponto de equilíbrio na abordagem educacional adotada (PAQUETTE; TRUDEL, 2018). Assim sendo, acredita-se que o primeiro passo dado pela FCB, em 2017, vai ao encontro das sugestões apontadas anteriormente para alterações paradigmáticas em propostas curriculares educacionais (BARR; TAGG, 1995; CULLEN; HARRIS; HILL, 2012; WEIMER, 2013): que sejam aplicadas paulatinamente considerando a realidade do contexto.

A percepção positiva, de modo geral, dos treinadores participantes corrobora com estudos internacionais sobre o potencial de programas de formação no contexto federativo (MISENER; DANYLCHUK, 2009; PAQUETTE et al., 2014). Além disso, reforça a premissa acerca da importância de adoção de estratégias de ensino interativas e reflexivas na condução de cursos desta natureza (CIAMPOLINI et al., 2019). Ademais, os relatos positivos acerca das temáticas de desenvolvimento do treinador, de atletas, e de valores durante a prática esportiva, e negativos acerca da temática de arbitragem e de gestão, 
sugerem compreensão dos treinadores sobre a importância de temáticas mais gerais para o aprimoramento da atuação profissional em detrimento às temáticas técnicas específicas normalmente presentes em propostas formativas tradicionais (PAQUETTE; TRUDEL, 2018). Este achado contraria uma perspectiva anterior sobre os interesses formativos de treinadores esportivos, os quais buscavam apenas direcionamentos técnicos que contribuíssem diretamente nas estratégias de treino (CUSHION; ARMOUR; JONES, 2003). Em vista disso, surgem dois questionamentos que necessitam ser respondidos em novos estudos: a) os treinadores estariam mudando os interesses formativos ao participar de programas de formação que abordam temáticas mais gerais à atuação? b) os treinadores teriam percebido positivamente a condução destas temáticas gerais se fossem adotadas somente estratégias de ensino diretivas e que não fomentassem a interação e reflexão?

A aproximação da formação investigada com a realidade acadêmicocientífica foi utilizada estritamente com o intuito de prestar suporte teórico às temáticas ministradas e às estratégias de ensino adotadas, o que foi percebido positivamente pelos participantes deste estudo. Já na Academia Brasileira de Treinadores (iniciativa do Comitê Olímpico Brasileiro para a formação de treinadores), a aproximação científica na estruturação da proposta curricular gerou a inclusão de temáticas como "introdução à pesquisa científica" e "métodos de pesquisa" assim como a necessidade do participante escrever um projeto final em formato de artigo científico (MILISTETD et al., 2016). Considerando as percepções negativas de treinadores em estudos prévios sobre a dificuldade de aplicação de teorias no contexto prático (NELSON; CUSHION; POTRAC, 2013) e a inclusão de conteúdos descontextualizados nos cursos sem relevância para a atuação profissional (MESQUITA et al., 2014), aponta-se um alerta para a inclusão exacerbada de aspectos acadêmico-científicos em programas desta natureza. Assim, o componente teórico das formações deve, sobretudo, nortear treinadores a desenvolver a "quality of mind", definida por Jones e Turner (2006) como a base de competências necessárias para lidar com as situações complexas da atuação profissional do treinador esportivo.

As percepções negativas identificadas oferecem direcionamentos para o aprimoramento dos próximos programas de formação da entidade envolvida neste estudo assim como para a criação de novas propostas de outras entidades. Entretanto, a preferência dos treinadores por sessões práticas durante o processo formativo demonstra o interesse por aprendizagens a partir da observação e experimentação. Nesta lógica, é importante ressaltar que estratégias de ensino desta natureza não devem proporcionar a reprodução de exercícios e o posicionamento dos treinadores no papel de atleta. Ou seja, devese adotá-la para oportunizar a reflexão individual e em grupo para as atividades propostas, a troca de experiências entre os participantes, bem como o desenvolvimento de competências importantes para a atuação qualificada (DIMENT, 2014; PAQUETTE et al., 2014). 


\section{CONSIDERAÇÕES FINAIS}

A oferta de um programa de formação continuada aos treinadores catarinenses de basquetebol compreende importante iniciativa da FCB para suprir a lacuna de programas nacionais promovidos pela CBB. Além disso, ressalta-se a importância da preocupação da FCB para estruturar um curso que atenda às demandas formativas de treinadores a partir de estrutura curricular e estratégias de ensino que valorizam o envolvimento ativo dos treinadores. Quanto à estrutura curricular dos cursos, a seleção de temáticas aplicadas à atuação e desenvolvimento profissional dos treinadores supera a perspectiva de apresentação de conteúdos técnicos e padronizados para utilização descontextualizada. Além disso, a preocupação com a adoção de estratégias de ensino diretivas interativas e reflexivas revela a transição de alguns indicadores de um paradigma instrucional para um paradigma de aprendizagem. Assim, acredita-se que a integração de outros aspectos do paradigma de aprendizagem assim como a elaboração de um currículo baseado no desenvolvimento de competências seja o próximo passo para o aprimoramento do programa de formação da FCB.

O fato de a maioria das percepções dos treinadores terem sido positivas, especialmente quanto às temáticas ministradas, às estratégias de ensino utilizadas e aos ministrantes envolvidos, sugere a contribuição do programa investigado no aprimoramento da atuação profissional dos participantes. Contudo, as percepções negativas identificadas dão suporte a futuras alterações nos programas de formação desta entidade, assim como podem ser consideradas por propostas formativas de outras entidades esportivas no Brasil. Neste sentido, a integração de sessões práticas de ensino ao longo dos cursos, a apresentação de conteúdos significativos e a elaboração de um cronograma coerente com a carga horária de trabalho dos treinadores poderão maximizar as potencialidades de aprendizagem de propostas desta natureza. Por fim, ressalta-se que além da construção deste estudo, um relatório foi redigido e diversas reuniões foram conduzidas com representantes da entidade no intuito de refletir sobre os resultados identificados e aprimorar futuros programas de formação.

\section{AgRADECIMENTOS}

Enaltecemos a receptividade da FCB para a condução deste trabalho, o qual foi realizado com apoio da Coordenação de Aperfeiçoamento de Pessoal de Nível Superior - Brasil (CAPES) - Código de Financiamento 001. 


\section{REFERÊNCIAS}

AZEVEDO, Andréa Maria Pires; OLIVEIRA, Glycia Melo; SILVA, Priscilla Pinto Costa; NÓBREGA, Thereza Karolina Sarmento; JÚNIOR, Marcílio Souza. Formação continuada na prática pedagógica: a educação física em questão. Movimento, v. 16, n. 4, p. 245-262, 2010. Disponível em:

https://seer.ufrgs.br/index.php/Movimento/article/view/11809/10854.

BARDIN, Laurence. Content Analysis. São Paulo: Edições 70, 2011.

BARR, Robert B.; TAGG, John. From teaching to learning - A new paradigm for undergraduate education. Change: The magazine of higher learning, v. 27, n. 6, p. 1226, 1995. Disponível em:

https://www.tandfonline.com/doi/abs/10.1080/00091383.1995.10544672.

BRASIL. Conselho Nacional de Educação. Resolução n 7, de 31 de Março de 2004. Institui as Diretrizes Curriculares Nacionais para os cursos de graduação em Educação Física, em nível superior de graduação plena. Diário Oficial [da] República Federativa do Brasil, Brasília-DF: CNE, 2004.

CIAMPOLINI, Vitor; MILISTETD, Michel; BRASIL, Vinicius Zeilmann; NASCIMENTO, Juarez Vieira do. Estratégias de ensino adotadas em programas de formação de treinadores: análise das publicações entre 2009 e 2015. Journal of Physical Education, v. 30, n. 1, p. 14, 2019. Disponível em: http://www.scielo.br/scielo.php?script=sci arttext\&pid=S244824552019000100400.

CÔTÉ, Jean; GILBERT, Wade. An integrative definition of coaching effectiveness and expertise. International Journal of Sports Science and Coaching, v. 4, n. 3, p. 307-323, 2009. Disponível em:

https://journals.sagepub.com/doi/abs/10.1260/174795409789623892.

CRESWELL, John W.; PLANO CLARK, Vicki L. Choosing a mixed methods design. Designing and conducting mixed methods research. 2. ed. Thousand Oaks: SAGE, 2011. cap. 3, p. 53-106.

CULLEN, Roxanne; HARRIS, Michael; HILL, Reinhold R. The learner-centered curriculum: Design and implementation. Hoboken, NJ: John Wiley \& Sons, 2012.

CUSHION, Christopher J.; ARMOUR, Kathy M.; JONES, Robyn L. Coach education and continuing professional development: Experience and learning to coach. Quest, v. 55, n. 3, p. 215-230, 2003. Disponível em:

https://www.tandfonline.com/doi/abs/10.1080/00336297.2003.10491800.

DIMENT, Gregory M. Mental skills training in soccer: A drill-based approach. Journal of Sport Psychology in Action, v. 5, n. 1, p. 14-27, 2014. https://www.tandfonline.com/doi/full/10.1080/21520704.2013.865005.

DRISKA, Andrew P.; GOULD, Daniel R. Evaluating a problem-based group learning strategy for online, graduate-level coach education. Kinesiology Review, v. 3, n. 4, p. 227-234, 2014. Disponível em:

https://journals. humankinetics.com/view/journals/kri/3/4/article-p227.xml.

FEDERAÇÃO CATARINENSE DE BASKETBALL - FCB. Clínica para técnicos reúne 90 profissionais na capital. Basquete SC: revista oficial da Federação Catarinense de Basketball, Florianópolis, v. 3, n. 8, p. 20-21, 2018. Disponível em:

https://issuu.com/fcb-basket/docs/basquetesc.008 ce45a766a567ca 
ICCE. International Sports Coaching Framework. Version 1.2. Champaign, IL: Human Kinetics, 2013. $60 \mathrm{p}$.

JARVIS, Peter. Globalization, lifelong learning and the learning society: Sociological perspectives. Abingdon: Routledge, 2007.

JONES, Robyn; TURNER, Poppy. Teaching coaches to coach holistically: Can ProblemBased Learning (PBL) help? Physical Education and Sport Pedagogy, v. 11, n. 2, p. 181202, 2006. Disponível em:

https://www.tandfonline.com/doi/full/10.1080/17408980600708429.

MESQUITA, Isabel; RIBEIRO, Joana; Santos, Sofia; MORGAN, Kevin. Coach learning and coach education: Portuguese expert coaches' perspective. Sport Psychologist, v. 28, n. 2, p. 124-136, 2014. Disponível em:

https://journals.humankinetics.com/view/journals/tsp/28/2/article-p124.xml.

MILISTETD, Michel; CIAMPOLINI, Vitor; SALLES, William das Neves; RAMOS, Valmor; GALATTI, Larissa Rafaela; NASCIMENTO, Juarez Vieira do. Coaches' development in Brazil: Structure of sports organizational programmes. Sports Coaching Review, v. 5, n. 2, p. 138-152, 2016. Disponível em: https://www.tandfonline.com/doi/abs/10.1080/21640629.2016.1201356.

MILISTETD, Michel; GALATTI, Larissa Rafaela; COLLET, Carine; TOZETTO, Alexandre Bobato; NASCIMENTO, Juarez Vieira do. Formação de treinadores esportivos:

Orientações para a organização das práticas pedagógicas nos cursos de bacharelado em Educação Física. Journal of Physical Education, v. 28, n. 1, p. 1-14, 2017. Disponível em: http://www.scielo.br/scielo.php?script=sci abstract\&pid=S2448-

$24552017000100302 \& \operatorname{lng}=$ en\&nrm $=$ iso\&tlng =pt.

MILISTETD, Michel; TRUDEL, Pierre; MESQUITA, Isabel; NASCIMENTO, Juarez Vieira do. Coaching and coach education in Brazil. International Sport Coaching Journal, v. 1, n. 3, p. 165-172, 2014. Disponível em:

https://journals.humankinetics.com/view/journals/iscj/1/3/article-p165.xml.

MISENER, Katie; DANYLCHUK, Karen. Coaches' perceptions of Canada's national coaching certification program (NCCP): Awareness and value. International Journal of Sports Science and Coaching, v. 4, n. 2, p. 233-243, 2009. Disponível em: https://journals.sagepub.com/doi/10.1260/174795409788549580.

MORGAN, Kevin; JONES, Robin L.; GILBOURNE, David; LLEWELLYN, David. Changing the face of coach education: Using ethno-drama to depict lived realities. Physical Education and Sport Pedagogy, v. 18, n. 5, p. 520-533, 2013. Disponível em:

https://www.tandfonline.com/doi/full/10.1080/17408989.2012.690863.

NELSON, Lee; CUSHION, Christopher; POTRAC, Paul. Enhancing the provision of coach education: The recommendations of UK coaching practitioners. Physical Education and Sport Pedagogy, v. 18, n. 2, p. 204-218, 2013. Disponível em: https://www.tandfonline.com/doi/full/10.1080/17408989.2011.649725

PAQUETTE, Kyle; HUSSAIN, Aman; TRUDEL, Pierre; CAMIRÉ, Martin. A sport federation's attempt to restructure a coach education program using constructivist principles. International Sport Coaching Journal, v. 1, n. 2, p. 75-85, 2014. Disponível em: https://journals. humankinetics.com/view/journals/iscj/1/2/article-p75.xml.

PAQUETTE, Kyle; TRUDEL, Pierre. The evolution and learner-centered status of a coach education program. International Sport Coaching Journal, v. 5, n. 1, p. 24-36, 2018. Disponível em: https://journals.humankinetics.com/view/journals/iscj/5/1/article- 
p24.xml.

PATTON, Michael Quinn. Qualitative evaluation and research methods. 2. ed. Beverly Hills: SAGE, 1990.

PIGGOTT, David. Coaches' experiences of formal coach education: A critical sociological investigation. Sport Education and Society, v. 17, n. 4, p. 535-554, 2012.

Disponível em: https://www.tandfonline.com/doi/full/10.1080/13573322.2011.608949.

STOSZKOWSKI, John; COLLINS, Dave. Sources, topics and use of knowledge by coaches. Journal of Sports Sciences, v. 34, n. 9, p. 794-802, 2016. Disponível em:

https://www.ncbi.nlm.nih.gov/pubmed/26222481.

TRUDEL, Pierre; GILBERT, Wade; WERTHNER, Penny. Coach education effectiveness. In: LYLE, John; CUSHION, Christopher J. (Ed.). Sports coaching: Proffessionalisation and practice. 1: Churchill Livingstone Elsevier, 2010. p. 135-152.

WEIMER, Maryellen. Learner-centered teaching: Five key changes to practice. 2. ed. San Francisco: Jossey-bass, 2013.

YIN, Robert K. Qualitative research from start to finish. New York: The Guilford Press, 2011. 